\title{
Book Review Essay
}

\author{
KOME - An International Journal of Pure \\ Communication Inquiry \\ Volume 8 Issue 1, p. 97-105. \\ (C) The Author(s) 2019 \\ Reprints and Permission: \\ kome@komejournal.com \\ Published by the Hungarian Communication \\ Studies Association \\ DOI: $\underline{10.17646 / \text { KOME.75672.36 }}$
}

Patricia Wallace The Psychology of the Internet. Second Edition. New York: Cambridge University Press, 2016, 392 pp.: ISBN: 978-1107079137

Jose van Dijck - Thomas Poell - Martijn de Waal The Platform Society. Public Values in a Connective World. New York: Oxford University Press, 2018, 226 pp.: ISBN: 978-0190889777 Lei Guo - Maxwell McCombs (eds). The Power of Information Networks. New Directions for Agenda Setting. New York, London: Routledge Francis and Taylor, 2016, 235 p. ISBN 9781138847750

Reviewed by: Monika Andok, Faculty of Humanities and Social Sciences, Pázmány Péter Catholic University, HUNGARY

The essay gives an overview of three remarkable recently published books, all of them focusing on Computer-mediated Communication (CMC) but from different viewpoints. In the second edition of her book The Psychology of the Internet, Patricia Wallace covers not only the psychological aspects of web 1.0 but also looks at that of the SNS. Jose van Dijck and her colleagues examine the changes caused by the Internet in society-which they call Platform Society - and give a genuine sociological approach. I intend to find out if the term Platform Society is only a new metaphor next to many others or offers an original access point to this field. The third book titled The Power of Information Networks was edited by Maxwell McCombs and Lei Guo. The authors of the book try to adapt the fifty-year-old agenda-setting theory to the Internet. In the article, I evaluate and compare these three volumes considering the disciplinary differences.

The first edition of Patricia Wallace's (Adjunct Professor at the Graduate School, University of Maryland University College) The Psychology of the Internet was published in 1999, translated into several languages and not only useful in scientific research but also in higher education. It has become compulsory reading for courses dealing with the relationship between computer-mediated communication and media. However, since the emergence of social network sites at the beginning of the 1980s, it has become increasingly apparent that the volume is relevant mainly to the network communication phenomena of the '90s. Thus, there was great interest in the release of the second edition of the book, in which Wallace deals with the psychological aspects of social media. In the preface of the second edition, the author also refers to how distant 1999 is: "With eight employees, Google had just outgrown its garage office, and Facebook founder Mark Zuckerberg immersed himself in classics as a high school sophomore" (p. xi) What has not changed, however, is Wallace's scientific commitment; she does not want to paint a happy portrait or unreasonably dark picture of the consequences for

Address for Correspondence: Andok Monika, email: andok.monika[at[btk.ppke.hu

Conflict of Interest: The author declares no conflicts of interest.

Article received on the 6th June, 2019. Article accepted on the 20th September, 2019.

Conflict of Interest: The author declares no conflict of interest. 
human behavior and social relationships. Wallace explains this when she says, "Instead, I describe - in a balanced way - what we actually know from research about the psychology of the Internet, citing both positives and negatives and raising many new questions" (p. xii). Wallace adheres to her promise as in the presented themes - for example, the impact of the use of digital games on the cognitive, emotional, or physical development of young people. In the book, she describes research on both the prosocial and negative impacts.

The structure of the second edition differs from its first volume. Of the chapters of the first edition, nine have been revised and combined: the first is titled "The Internet is a psychological context," the second "Your online persona: the psychology of impression formation," the third "Group dynamics on the Internet," the fourth "The psychology of online aggression," the fifth "Linking and loving on the net: the psychology of interpersonal attraction," the sixth "Altruism on the net: the psychology of prosocial behavior," the ninth in the volume "Gender issues and sexuality on the Internet," the eleventh "The Internet as a time sink" and partly the twelfth "Nurturing life on the Internet." Besides these, the second edition was enriched by three new chapters, the seventh chapter in the volume is titled "The psychology of online gaming," chapter eight "Child development and the Internet," and chapter ten "The psychology of online privacy and surveillance."

Wallace, as a psychologist, is not primarily interested in network technology, but in network as a human behavior environment and how people behave in this environment other than the offline world. "Broadly defined, cyberspace presents a wide range of experiences, and we need a special kind of taxonomy - one that divides up the known virtual world into betterdefined spaces that shares features from psychological perspective" (p. 6). The environments listed in the first and second editions are, of course, different, as the second edition includes social media environments as well. The taxonomy of the first volume mentioned the following environments: the World Wide Web, electronic mail, asynchronous discussion forum, synchronous chat, Mud (Multiuser Dungeon), meta world, and live interactive video. In the second edition, eleven environments are separated by Wallace, which are: (1) the web, (2) the deep web and dark web, (3) email, (4) asynchronous discussion forums, (5) synchronous chat and instant messages, (6) blogs, (7) social networks, (8) Twitter and texting, (9) virtual worlds and virtual realities, (10) interactive video, and (11) mobile apps. The first chapter of this volume contains a brief description of these environments, as well as the special features of online language use. In this initial chapter, Wallace also lists theories that have attempted to describe the psychological dimensions of media use. She emphasizes John Short's social presence theory (Short, Williams, and Christie 1976), Daft and Lengen's (1986) media richness theory, Walther's (2008) social information processing theory, the social identity model of deindividualization developed by Spears and his colleagues (Spears et al 2014) and finally the uses and gratifications approach.

The second chapter of the book deals with the similarities and differences between offline and online impression formation, and also covers the impression formation (profile photos, number of friends) on social networks. The author presents a number of interesting research studies and data about the different social media usage of the different types observed by research studies based on the "Big Five" personality traits used in psychology. (The "Big Five" personality traits: extraversion, openness to experience, agreeableness, conscientiousness, neuroticism.) For example: "The observers related the people with funny email addresses or fantasy characters in the address as more extraverted, and they thought the same about Yahoo! users" (p. 35). Wallace also deals with the issue of how to manage impressions for multiple audiences. "A wall posting and photo from a friend who attended a party with you last night might not be exactly what you'd like your grandmother or employer to see. This phenomenon is called context collapse as multiple audiences merge in ways that make it much more difficult to manage an 'authentic' impression" (p. 46). At the end of the 
second chapter, the author discusses the question of narcissism, whether the younger generation is more narcissist than the elder, and whether the online environment promotes narcissism.

The third chapter of the book is called "Group dynamics on the Internet." Wallace captures the main difference between offline and online social media groups as follows: "[But] while human groups have always existed, the Internet has not, and its effects on group dynamics are profound. ... Within social networks, we create our own groups with ourselves in the centre" (p. 57). The author gives a detailed description of how conformity works, group norms, and polarization on the Internet. Regarding polarization, she speaks of the new phenomenon that the literature refers to as the echo chamber according to Sunstein. "The technology makes it quite easy not just to find people of like mind, but to restrict our own access to just the sources that tend to agree with us" (p. 78). In this chapter, Wallace summarizes the research studies on the effectiveness of online workgroups: how the different social status of group members affects the decision-making and whether minority opinions are taken into consideration during the decision-making process. And like in the first edition, she also confirms in the current volume that brainstorming is not effective or successful, either offline or online (p. 89-91).

"The psychology of online aggression" is the fourth chapter in which she deals with the much-discussed issue of cyberaggression, mentioning a number of research studies on this topic. For example, Buckels and her colleagues surveyed a sample of Internet users and found that 5.6 percent reported that they enjoyed trolling (p. 110). Wallace shares the opinion of many scholars when stating: "From a psychological perspective, online environments have quite a few features that not only encourage aggressive behavior but amplify and prolong its impact" (p. 116). These features are: anonymity, physical distance, amplification, permanence, and the use of multimedia. At the end of the chapter, the psychologist offers strategies that can reduce online aggression.

The fifth, titled "Linking and loving on the net: the psychology of interpersonal attraction" similarly to the first edition, is begun by looking at the factors that influence interpersonal attraction in the offline environment: physical attractiveness, proximity, familiarity, similarity, humor, "you like me, I like you" spiral. Then the author shows how these factors work in digital media, complementing this with jealousy research. "A survey study of college students found a strong association between amount of time spent on Facebook, feelings of jealousy and jealous behavior" (p. 141). Wallace also writes about a very recent research field related to this, which is post-breakup Facebook surveillance. Online dating, as well as its economic aspects, can be connected to the topic, too, which researchers have also noticed: "Dating sites attempt to appeal to potential customers in many different ways, leading to the proliferation of niche sites and what the marketers call the 'long tail' phenomenon" (p. 143). It is generally true that online dating represents a fundamental change in the way people seek love and romance.

The sixth part of the book is "Altruism on the net: the psychology of prosocial behavior." Wallace begins the chapter by highlighting three areas in which the Internet has been particularly prominent, namely volunteerism, fundraising and crowdfunding, and online support groups. While explaining each of the three areas and opportunities in detail, she also answers the question of why people support each other. "How do online environments affect who you are most willing to help? Just as in face-to-face settings, gender and similarity play a role" (p. 183). Among the editors of Wikipedia, for example, we can find more men-80 percent; by contrast, women are more likely to be in the support groups where people are sharing personal problems.

"The psychology of online gaming" is the seventh chapter and is the first thematic unit that is the novelty of the second edition. Wallace presents the psychological dimensions of games by dividing them into playing genres. Based on focus group researches, the main motivations of online gamers are mentioned as challenge, competition, diversion, arousal, 
fantasy and social interaction (p. 199). She refers to examinations on both the negative and positive consequences of the games. As a negative sign, violent video games reduce our ability to empathize with people who are suffering and in need. They desensitize us to human pain. But she also shows the other side, the games have cognitive, emotional and social benefits, including the Proteus effect. (The Proteus effect describes a phenomenon in which the behavior of an individual, within virtual worlds, is changed by the characteristics of their avatar.) In addition, she discusses how gambling and gamification can be applied in education. She also honestly says that many of these games will soon fall short because they are "chocolate-covered broccoli, and the players recognize the difference" (p. 224).

"On a typical evening, twelve-year-old Jason splits his time between texting friends, completing maths homework, commenting on YouTube videos, playing video games and listening to music." Thus, Wallace begins the eighth chapter of her book titled "Child development and the Internet" (p.228). It is also a novelty of the second edition, and the American psychologist conscientiously presents the complexity of the issue. Within the impact of the Internet on cognitive development, the author primarily describes the benefits of online learning. That is no wonder since she was Chief Information Officer and Associate VP at University of Maryland University College, where she was closely involved in UMUC's efforts to build and launch a worldwide, virtual university. On the subject of physical development, she emphasizes two important negative effects: one is the decline in sleep time and the other is the same in physical exercise. In terms of social and emotional development, it is about the formation of friendships and the development of identity. More exactly about one of the most important issues regarding the Internet and psychology, which is cyberbullying. First, the author clarifies what the difference is between offline and online bullying. "While traditional bullying occurs mostly in school or school buses, cyberbullying is a $24 / 7$ phenomenon. ... potential audience for cyberbullying is vast. ... perpetrator anonymous" (p. 252). One of the main reasons for bullying is the lack of empathy, and this is rather a typical form of aggression of high school girls. The chapter presents a number of useful practices that parents can apply to promote the good and avoid the bad things and help their children.

The ninth chapter, "Gender issues and sexuality on the Internet" contains only minor changes to the 1999 volume. The author introduced a new subsection titled "The Internet and LGBT Issues" (p. 276-278) in the text.

Although the book was published before the Facebook scandal, the tenth chapter deals with "The psychology of online privacy and surveillance." After reviewing the theme of history and meaning of "privacy," it connects to the most important online phenomena. One is the loss of control over the content we upload, and the other is the privacy paradox. "The privacy paradox is that people say they are concerned about the issue; they also say they have at least some knowledge about how to configure privacy settings. But at the same time, their behavior often does not mirror those concerns" (p. 301). In the chapter, Wallace also deals with the new business models based on the big data and with the topic of surveillance. In the perspective of the future of privacy, she quotes both pessimistic and optimistic authors, but she has committed to the optimist herself (p. 318).

We are increasingly always online. This phenomenon is dealt with in chapter eleven, "The Internet as a time sink." Continuous online presence is a problem for work-life balance, as it can easily lead to a $24 / 7$ work week that has a negative impact on family life. Related to this, Wallace mentions the boundary theory. "Boundary theory explores the way people manage the boundaries for work life and home life, how we make decisions about how permeable any particular boundary should be, and how our roles shift as boundaries are crossed" (p. 323). In this chapter, the author refers to the issue of addiction, which was identified as a mental illness only after the publication of the book, in 2018. Moreover, ending the chapter, she talks in short about the possible treatments as well. 
The closing chapter of the volume, "Nurturing life on the Internet," draws attention to the importance of digital literacy. And Wallace again summarizes the purpose of writing: "I have no bulleted list of 'ten ways to make the Internet a better place for human habitation' in this book. Human behavior is far too complex for such a distillation, and the range of experiences you might have as you touch down in different corners of the Internet is much too great. Yet throughout this book, you have seen research showing how we are affected by the net and how our own behavior can have positive or negative consequences on our net companions" (p. 347-348).

The book is a high-quality, comprehensive presentation of the psychological effects of the Internet. And as the first edition became a university coursebook, the second edition is likely to do so.

Moving forward to The Platform Society. Public Values in a Connective World by Jose van Dijck, Thomas Poell and Martijn de Waal, this venue covers the editors' projects over the past few years concerning the following topics: what are the platforms and how do they work; how can we conceptualize urban transport, health care, education, and governing in the platform society. In other words, what roles do online platforms play in the organization of public values in western societies? Although their effort is multidisciplinary, they cannot offer a well-elaborated new paradigm because they work with a moving target.

The key concept of the Dutch scholars' book is the platform society. "The term refers to a society in which social and economic traffic is increasingly channeled by an (overwhelmingly global) online platform ecosystem that is driven by algorithms and fuelled by data" (p. 4). According to the authors, "Platforms do not reflect the social: they produce the social structure we live in. ... the term platform society emphasizes that platforms are integral part of society" (p. 2). It is claimed that platforms are neither neutral nor value-free constructs; they come with specific norms and values inscribed in their architecture, for example, social media make certain things visible while hiding others (p. 3, 32).

The largest most influential infrastructural platforms are the so-called Big Five: Alphabet - Google, Apple, Facebook, Amazon, and Microsoft. These companies constitute the core of the platform society's ecosystem. Next to the industrial platforms, van Dijck identifies sectoral platforms too, which offer digital services for one specific sector such as health (PatientsLikeMe - PLM), education (Massive Open Online Courses - MOOCs), news (Google News), and transport (Uber). These platforms can be understood as a multisided market, too. The media researchers analyze all three fields in detail through examples of several other sectoral platforms. In particular, how these platforms (which operate with private benefit and corporate gain) affect public values and common goods. Van Dijck raises the question directly: "But who will pay for the collective costs?" (p. 2)

In the second chapter, the scholars identified three main mechanisms as driving forces underlying this platform-based ecosystem, while filter and steer social interactions: datafication, commodification, and selection. These mechanisms work through the interplay between technology, commercial strategies, and user practices (p. 32). "Datafication is the transformation of social action into online qualified data, thus allowing for real-time tracking and predictive analysis ... datafication as a legitimation means to access, understand and monitor people's behavior and it is becoming a leading principle" (Mayer-Schönberger \& Cukier, 2013; van Dijck, 2014: 198). According to van Dijck, the mechanism of commodification involves platforms transforming online and offline objects, activities, emotions, and ideas into tradable commodities. These commodities are valued through at least four types of currency: attention, data, users, and money (p. 37). Datafication and commodification are closely related to the ways in which platforms steer user interaction through the selection or curation of most relevant topics, services, and actors. The authors discuss three types of selection, namely personalization, reputation and trends, and moderation. 
All of them will be elaborated in the forthcoming chapters concerning the analyzed sectors, urban transport, news, healthcare, and education.

The Dutch researchers differentiate three levels among the platforms: single platforms are on the micro-level, platform ecosystems are on the meso-level, and platform societies are on the macro-level. But we cannot study them in isolation from social and political structures. The authors identified the key elements of the single platform are "fuelled by data, automated and organized through algorithms and interfaces, formalized through ownership relations driven by business models, and governed through user agreements" (p. 9).

Platform society can be characterized as a series of confrontations between different value systems, contesting the balance between private and public interests. The book explains how online platforms penetrate a specific field and will be embedded in the ecosystem as a whole, and which public values are championed. Some of these values have already received much attention, such as privacy, accuracy, safety, and consumer protection. But other values do not have, for example, fairness, equality, solidarity, accountability, transparency, or democratic control (p. 3).

The third chapter of the book offers a relevant frame to understand the platformization of news. In sum, news business models change because the rise of platforms leads to a fundamental reorganization of economic relations around platforms as multisided markets. Key values such as journalistic independence, trustworthiness have come under mounting public scrutiny as connective platforms have come to steer the conditions of production and distribution.

The next sector that they analyze in the fourth chapter is urban transport, and their main example is Uber. Platformization affects the entire sector, effectively blurring the division between public and private transport modalities. The authors focus on two central public values in this chapter, the quality of urban transport and the organization of labor and workers' rights. They mention an important aspect "... to regard complementors, connectors, and infrastructural platforms as part of the sector in which they operate. As we have seen, platforms like Uber place themselves outside the sector. While this allows them to operate more cost-efficiently, it also means the company does not contribute to the cost of maintaining public values such as quality, accessibility, comprehensiveness and the organization of labor right" (p. 95).

The health sector, like the sectors of urban transport, news, and hospitality, is currently undergoing its own platformizatition, which is discussed in the fifth chapter. The insights into specific health platforms help the scholars reflect on the conflicting public values as at stake in this debate: the concern for privacy versus the benefit of personalized medicine and the privatization of data by corporate owners versus the accessibility of health data and knowledge of public research (p. 98). They introduce services like DoctorDiagnose, WebMD, Virtual Doctor.

The transition toward a platform society disrupts traditional pedagogies of learning and teaching. Chapter 6 concentrates on education and the authors investigating how platformization is profoundly affecting the very idea of education as a common good. They clarify how datafication and personalization can be leveraged toward enhancing the common good if organized as open initiatives and supported by public institutions, governments, and civil society actors ( $\mathrm{p}$ 119). Personalized learning means that the online system adapts to each student's learning needs and abilities to optimize individual performance and motivation. This process raises many social, ethical, and normative questions concerning the kind of education children may engage with in the future (p.134).

In the last chapter, the authors shift their focus from the analytical to the normative aspects of the topic and try to identify who is or should be responsible and accountable for anchoring public values in the platform society? But the focus in the book is not so much on developing a normative governance model for the platform society but rather on analyzing 
negotiations in the process of platformization in order to reveal underpinning mechanisms, patterns, and stakes. Van Dijck and her colleagues introduce a range of public values: the safety of data traffic, privacy, transparency, power to control our personal data, responsibility, accountability, etc. (p. 140).

In sum, we can say that we are very thankful for the thoughtful aspects of the book. But even after raising good questions and analyzing the fields, we cannot consider the issue closed. As a consequence, The Platform Society is more useful for researchers than students.

The third reviewed book adapts the old, well-known media effect theory, the Agenda Setting Theory, to the Internet. Since the early 2010s, studies have been published by Lei Guo that examined the contents of CMC based on the Agenda Setting Theory (Guo, 2013). The larger scientific community came to know her in 2011 when she presented about the third level of AS at the annual conference of the International Communication Association. This volume praises the editorial work of Maxwell McCombs and Lei Guo.

The book introduces a third level of agenda-setting theory called Network Agenda Setting Model (NAS), presenting both theoretical and methodological details and contents of many empirical studies, case studies, too. The first chapter deals with a broader perspective on agenda-setting. The second chapter is divided into two large units, the first showing research studies in public affairs and political communication, the second focusing on strategic communications and public relations. Finally, the third chapter shortly summarizes and closes the volume.

The original Chapel Hill study (McCombs-Show 1972) is now referred to as first-level agenda setting. It asserts that the public considers objects that are prioritized in the news media as the most important. The second level—attribute agenda setting - focuses on the news determining not only what we think about, but also affecting how we think about a given topic. "The NAS model turns attention to the networked media effects. The model focuses on the networked relationships among issues, attributes, and other elements rather than the salience transfer of individual elements per se" (p. 5). In the first chapter, Guo gives a theoretical and methodological explanation of the NAS model. She differentiates the media network agenda (the network of nodes represent the news coverage) and the public network agenda (the network of nodes represent public opinion). The NAS analysis compares the two network agendas and measures the degree of correlation.

Guo elaborated the mechanism of information-processing and then discussed the questions of framing and priming. She suggests that the NAS is an effective tool to detect the associative framing. "Based on the NAS model, researchers consider frames as complex patterns of non-hierarchical associations between different concepts and term this media effects process associative framing" (p. 12). Guo offers three additional possible dimensions for analysis, which are the following: the level of elaboration, valence, and direction. The level of elaboration, whether the association is implicit or explicit, is an important factor that can affect the network agenda-setting effect. "On the reception side, there is a question about to what extent audience members elaborate on message associations as a result of media effect" (p. 14). The second suggested dimension of the media and public network agenda is the potential valances of message association, where these ties can be positive, negative or neutral. And the final dimension is the direction of various message associations.

The American researcher gives us well-elaborated methodological guidance, too. She explains some approaches to examine the NAS model. The network agenda-setting analysis consists of five steps, which are the following:

"Step 1: Operationalize the media network agenda. (Content Analysis)

Step 2: Operationalize the public network agenda. (Public survey, mind mapping, social media analysis) 
Step 3: Compute the degree of correlation between the media and the public network agenda. (Quadratic Assignment Procedure-QAP, UCINET)

Step 4: Examine the causal relationship between the media and public network agenda.

Step 5: Visualize the media and public network agenda. (NetDraw, Gephi)" (p. 19, 23-31).

The volume contains 11 studies that rely on this methodological background. In the final article of the first chapter, Carroll Craig specified four different types of relational agendas located within three domains along a continuum. "The three domains of relationships identified were uniplex, duplex and multiplex, with two types of multiplex relationships: micro and macro" ( $p$. 45). She presents a lot of cases: the example of a uniplex association comes from the linking of Iraq and/or Saddam Hussein to the events of 9/11. Duplex relationships concern the limited number of configurations created by two linkages connecting three nodes. Multiplex relationships have referred to the extent to which three or more nodes are linked together, and the NAS focuses on multiplex associations.

The first part of the second chapter of the book encompasses seven empirical research studies concerning the fields of Public Affairs and Political Communication.In their article, Vargo and Guo explore how the NAS model can work with big social data. "The widespread availability and accessibility of big social data also makes it possible to examine media effects during an extended period of time" (p. 64).

Sharon Meraz tries to test the operation of the NAS model at the issue level between traditional media and Twitter communities. In her study, she unfolds how networks impact the agenda-setting theory between popular, political discussion communities, and traditional media (she does so by analyzing 43 days' worth of articles from The New York Times and Washington Post in 2014). In doing so, she examines how the NAS model helps explain the ebb and flow of everyday issue discussion between social media political discussion communities and traditional media (p. 67). This process is referred to in the literature as intermedia agendasetting.

Nirit Wiess-Blatt examines in her article- "Role of Tech Bloggers in the Flow of Information"- the impact of news media and tech blogs. While the study integrates two research traditions, namely the NAS model and the two-step flow of communication, it found significant intermedia agenda-setting effects between tech blogs and mainstream media coverage. She tries to identify tech bloggers as opinion leaders (p. 98).

Ardèvol-Abreu and Saldaña examined the trend in US public opinion regarding the drug issue. Kim and Min analyzed the network attribute agenda of a public issue, nuclear energy in South Korea. Comparative research studies can also be found in the book edited by Gou and Maxwell, for example Hellmueller and Mellado's article in which they examine journalistic role performance in the US and Chile. "The application of the NAS model in this study allows us to investigate the media agenda and journalist professionalism from a networked perspective" (p. 128). The Texas University International Journalism Research Coalition's study offers an international (US, Poland, Spain, Columbia, Mainland China, and Taiwan) comparison of network attribute agendas about the news coverage of the Iraq War in 2003. "Regarding the importance of cultural and political similarity, the evidence clearly favours political alignment over cultural affinity. Five of the seven correlations above the median involve four governments with strong political alignments on the Iraq War-The United States, Spain, Poland, and Taiwan" (p. 226).

The second part of the second chapter of the book leads the readers to the fields of strategic communication and public relations. All four empirical papers deal with the issue of agenda building.

Kiousis and Ragas reveal how scholars can connect the research tradition of political public relations and NAS. Ilia, Bantimaroudis, and Meggiorin investigated the influence of 
press releases from four global biometric corporations (Identix, Sagem Morpho, Viisage, Visionics) on their media coverage. Etter and Vestergraad unfold NAS in a public relations domain, with a focus on Greenpeace's campaign against Nestle's use of palm oil in certain products. Lisa Weidman analyzes the attributes of Oregon wine in her article "Attributes of a Cultural/Consumer Product."

In sum, the NAS model, the third level of agenda-setting theory, asserts that the ways in which the news media associate different objects, attributes, and other pieces of information in depicting social reality will have a significant impact on how members of the public link these elements in their mind (p. 19).

We can agree with Guo, who wrote: "The NAS model does not intend to entirely revolutionize our previous thinking on the effects on mediated communication. Instead it seeks to add more theoretical links to the media effects models" (p. 15).

All three volumes are important contributions to new media, CMC research, though from the different disciplines of psychology, sociology, and media effect theory. All of them have the strength to include not only theoretical review but several empirical research as well. While the books edited by Gou and McCombs and van Dijck's Platform Society are more useful for media researchers, Wallace's The Psychology of the Internet holds its place as a university coursebook.

\section{References}

Daft, R. L., \& Lengel, R. H. (1986). Organizational information requirements, media richness and structural design. Management Science, 32 (5), 554-571.

Guo, L. 2013 Toward the Third Levelof Agenda-Setting Theory. A Network Agenda Setting Model. In. T. Johnson (Ed.), Agenda setting in a 2.0 world: New Agendas in Communication, pp. 112-133. New York: Routledge.

Mayer-Schoenberger, V. and K. Cukier. (2013). Big Data. A Revolution that will transform how we live, work, and think. London: John Murray Publishers.

McCombs, M. - Show, D. (1972). Agenda-setting functions of mass media. Public Opinion Qurterly, 36, 176-187. CrossRef

Short, J., Williams, E., \& Christie, B. (1976). The social psychology of telecommunications. New York, NY: Wiley.

Spears, R., Lea, M., Postmes, T., \&Wolbert, A. (2011). A SIDE look at computer-mediated interaction: Power and the gender divide. In Z. Birchmeier, B. Dietz-Uhler, \& G. Stasser (Eds.), Strategic uses of social technology: An interactive erspective of social psychology, pp. 16-39. New York, NY: Cambridge University Press.

van Dijck, J. (2014. Datafication, dataism and dataveillance: Big Data between scientific paradigm and ideology. Surveillance \& Society 12(2): 197-208. CrossRef

Walther, J. B. (2008). Social information processing theory. In L. A. Baxter \& D. O. Braithewaite (Eds.), Engaging theories in interpersonal communication: Multiple perspectives (pp. 391-404). Thousand Oaks, CA: Sage Publications. 